\title{
Kişisel Bilgiler ve Günlük Aktiviteler Gibi Tetikleyicilerin Migren Atağı Üzerindeki Etkilerinin Makine ve Derin Öğrenme Yaklaşımları ile Analizi
}

\author{
Caglar Gurkan ${ }^{*}$, Sude Kozalioglu ${ }^{2}$, Merih Palandoken ${ }^{1,3,4}$ \\ 1* İzmir Katip Çelebi Üniversitesi, Mühendislik ve Mimarlık Fakültesi, Elektrik Elektronik Mühendisliği Bölümü, İzmir, Türkiye, (ORCID: 0000-0002-4652-3363), \\ caglar.gurkan@outlook.com \\ ${ }^{2}$ Eskişehir Osmangazi Üniversitesi, Mühendislik ve Mimarlık Fakültesi, Elektrik Elektronik Mühendisliği Bölümü, Eskişehir, Türkiye, (ORCID: 0000-0002-2377- \\ 1989), sudekozalioglu@gmail.com \\ ${ }^{3}$ İzmir Katip Çelebi Üniversitesi, Yapay Zeka ve Veri Bilimi Uygulama ve Araştırma Merkezi, İzmir, Türkiye, (ORCID: 0000-0003-3487-2467), \\ merih.palandoken@ikc.edu.tr \\ ${ }^{4}$ İzmir Katip Çelebi Üniversitesi, Akıllı Fabrika Sistemleri Araştırma ve Uygulama Merkezi, İzmir, Türkiye, (ORCID: 0000-0003-3487-2467), \\ merih.palandoken@ikc.edu.tr
}

(1st International Conference on Applied Engineering and Natural Sciences ICAENS 2021, November 1-3, 2021)

(DOI: 10.31590/ejosat.1014212)

ATIF/REFERENCE: Gurkan, C., Kozalioglu, S. \& Palandoken, M. (2021). Kişisel Bilgiler ve Günlük Aktiviteler Gibi Tetikleyicilerin Migren Atağı Üzerindeki Etkilerinin Makine ve Derin Öğrenme Yaklaşımları ile Analizi. Avrupa Bilim ve Teknoloji Dergisi, (28), 12331236.

$\ddot{O} \mathbf{z}$

Dünyadaki en yaygın üçüncü hastalık olan migren, hastaların yaşam kalitesini olumsuz etkilemektedir. Kişisel bilgilerin ve genetik özelliklerin migren hastalığı üzerindeki etkisi bilinmektedir. Yapay zekanın kullanımıyla sağlık alanındaki verilerin analiz edilmesi oldukça önemlidir. Bu çalışmada kullanılan veri seti 'migren atağı olan' ve 'migren atağı olmayan' günlerde elde edilen ve çeşitli migren tetikleyicilerini içeren 4579 örnekten oluşmaktadır. Bu tetikleyicilerin etkisi ile gün içinde migren atağı olan veya olmayan hastalar makine öğrenmesi ve derin öğrenme yöntemleri kullanılarak analiz edilmiştir. Tüm analizler içerisinde, en yüksek kestirimci performans çok katmanlı algılayıcı algoritması tarafından \%99.7 doğruluk oranı ve \%97.7 F1-skoru ile elde edilmiştir.

\section{Analysis of the Effects of Triggers Like Personal Information and Daily Activities on Migraine Attack with Machine and Deep Learning Approaches}

\begin{abstract}
Migraine the third most common disease in the world, is negatively affected the quality of life of patients. The effect of personal information and genetic characteristics on migraine disease is known. It is quite important to analysed data in the field of health with the use of artificial intelligence. The data set used in this study consists of 4579 samples obtained on 'with a migraine attack' and 'without a migraine attack' days and containing several migraine triggers. With the effect of these triggers, the patients with or without migraine attacks during the day were analyzed using machine learning and deep learning methods. Among all analyses, the highest predictive performance has been obtained by the multilayer perceptron algorithm with an accuracy of $99.7 \%$ and an F1-score of $97.7 \%$.
\end{abstract}

Keywords: Migraine attacks, Migraine triggers, Artificial intelligence, Machine learning, Deep learning

* İlgili Yazar: caglar.gurkan@,outlook.com 


\section{Giriş}

Migren, dünyadaki en yaygın üçüncü hastalık olmakla birlikte hastaların yaşam kalitesini en fazla olumsuz etkileyen altıncı hastalıktır. Nörolojik hastalıklar içersinde ise en yaygını olan migren dünya çapında 1 milyar insanın hayatını olumsuz yönde etkilemektedir. Ek olarak, 4 milyondan fazla yetişkinin, ayda en az 15 gün migren ağrısı yaşadığı bilinmektedir (Migraineresearchfoundation.org, 2015). Migren hastalarının genellikle yüksek sese ve 1şı̆̆a karşı duyarlılıkları bulunmaktadır (Mayo Clinic, 2020). Migren hastalığı bulunan kişiler günlük hayat içerisindeki işlerini bile tamamlamakta zorlanabilmektedirler. Çoğu araştırma migren tedavisine veya ağrılarını minimuma indirmeye yönelik yapılmıştır. Bununla birlikte migren ağrılarının nedenlerinin de araştırılması gerekliliği bulunmaktadır. Son yıllarda, yapay zeka algoritmalarının sağlık alanında sıklıkla kullanılması bu alanda yapılacak tanı ve tedavi gibi çalışmaları kritik bir noktaya getirmiştir.

Migren oluşumlarının önceden tahmin edilmesi hem önlenmesi hem de hafifletilmesi açısından oldukça önemlidir. Böylelikle hastalar baş ağrıları konusunda daha çok bilgi sahibi olabilirler. Baş ağrılarını tetikleyen durumlar önlenebilir. Sonuç olarak ise hastalar şiddetli migren ağrılarından kurtulabilirler. $\mathrm{Bu}$ destekleyici sağlı sisteminin oluşturulması için makine öğrenmesi ve derin öğrenme yöntemleri, belli migren tetikleyicileri ile migren oluşma durumu arasındaki ilişkiyi analiz etmek için kullanılabilir.

$\mathrm{Bu}$ çalışmanın başlıca amacı ise migren hastalığı üzerindeki tetikleyicilerin kullanımı ile birlikte doğru bir migren atağı tahmin sisteminin oluşturulmasıdır. Bu bakımından tahmin sürecine dahil edilen migren tetikleyicisinin sayısı önemli bir konudur. $\mathrm{Bu}$ bağlamda 22 adet tetikleyiciyi ve 4579 adet örneği içeren bir veri seti, migren atağ 1 yaşanan veya yaşanmayan gün olmak üzere iki sınıfta sınıflandırma görevinde deneysel analiz aşamasında kullanılmıştır. Çalışmada kullanılan sınıflandırıcı algoritmalar ise naive bayes (NB), destek vektör makineleri (DVM), k-en yakın komşu (KNN), karar ağaçları, lojistik regresyon (LR), rastgele orman, Gradyan Artırma Makineleri (GBM), Ekstrem Gradyan Artırma (XGBoost), hafif gradyan artırma makineleri (LightGBM), kategorik hızlandırma (CatBoost), çok katmanlı algılayıcı (ÇKA) şeklindedir. Tüm bu sınıflandırıcı algoritmalar içerisinde, ÇKA algoritması \%99.7 doğruluk oranı ve \%97.7 F1skoru ile en yüksek tahmin performansını elde etmiştir. Sonuç olarak, yüksek bir başarım oranına sahip olan ve migren atağının tahminlenmesini sağlayan bir karar destek sistemi bu çalışmada geliştirilmiştir.

Çalışmanın geri kalan kısmı ise şu şekilde düzenlenmiştir; 2 . bölümde benzer çalışmalardan söz edilmiştir, 3. bölümde kullanılan veri setinin özellikleri belirtildikten sonra çalışmada kullanılan yöntem, yazılım ve donanım bilgileri aktarılmıştır, 4 . bölümde kullanılan yöntemler ile elde edilen sonuçlar analiz edilmiş, yorumlanmış ve karşılaştırılmıştır, 5. bölümde ise çalışma ile igili son bilgiler aktarılmıştır.

\section{2. İlgili Çalışmalar}

$\mathrm{Bu}$ bölümde ilgili alandaki benzer önceki çalışmalar aktarılmaktadır.

Berengueres ve Cadiou geliştirdikleri mobil uygulama aracılığı ile yarım milyondan fazla migren hastasına ait bilgileri kullanarak kendi veri setlerini oluşturmuşlardır. Sonrasında bu verileri manuel olarak analiz etmişlerdir (Berengueres \& Cadiou, 2016). Liu vd. migren ağrılarının nasıl yönetileceğini öğrenmek için video, ses ve animasyonlu talimatlar ile hastaları yönlendiren bir uygulama geliştirmişlerdir. Ek olarak, hastaların ağrılarını kendileri tarafından rapor ettikleri çeşitli tetikleyicileri içeren bir baş ağrısı günlüğü oluşturmuşlardır. Fakat hastaların kendi ağrılarını rapor ettikleri bu sistem, hastaların, migrenin tıbbi niteliklerini yeterince bilmemesi nedeni ile objektif olmayan sonuçları meydana getirmiştir. Makine öğrenimini sürece dahil edidiğinde, insan hataları azalırken ve sonuçlar daha güvenilir hale geldiğini de aktarmışlardır (Liu, Holroyd, Zhu, Shen, \& Zhou, 2010). Garcia-Chimeno vd. 52 migren hastasina (15 kontrol grubu, 19 sporadik migren hastası ve 18 kronik migren ve aşırı ilaç kullanımı olan migren hastası) bir anket uygulamışlardır. Elde ettikleri verileri ise NB, DVM ve AdaBoost gibi makine öğrenmesi tabanlı sınıflandırıcıları kullanarak analiz etmişlerdir. Ayrıca çalışmada farklı öznitelik seçimi algoritmalarını da test etmişlerdir (Garcia-Chimeno, Garcia-Zapirain, GomezBeldarrain, Fernandez-Ruanova, \& Garcia-Monco, 2017).

\section{Materyal ve Yöntem}

\subsection{Veri Seti ve Veri Ön İşleme}

Kullanılan veri seti, 'Analysis of Trigger Factors in Episodic Migraineurs Using a Smartphone Headache Diary Applications' başlıklı çalışmada oluşturulmuştur (Park, Chu, Kim, Park, \& Cho, 2016). Bu veri seti bir anket yöntemi ile elde edilirken, katılımcılara çeşitli tetikleyicilere cevap olarak bire denk gelen 'Evet' veya sifira denk gelen 'Hayır' cevabını vermeleri istenmiştir. Veri setinde; stres, uyku durumu, egzersiz yapma durumu, yorgunluk, hormonal değişiklikler, duygusal değişiklikler, hava değişiklikleri, güneş 1şığı, gürültü, aydınlatma durumu, kokular, alkol tüketimi, beslenme durumu, kafein tüketimi, sigara tüketimi, tüketilen besinin türü, seyahat vb. gibi çeşitli 22 adet tetikleyici yer almaktadır. Bununla birlikte, geçmiş tetikleyicilerden gelen 0 ve 1 cevaplarının sayısal toplamı da bir öznitelik olarak veri setine eklenmiştir. $\mathrm{Bu}$ çalışmada, migren tetikleyicileri, iki sınıfta sınıflandırma görevi olan 'migren atağı yaşama' veya 'migren atağı yaşamamayı' tahmin etmek için kullanılmıştır.

Veri seti migren atağ 1 yaşanan veya yaşanmayan günlerde elde edilen 4579 adet örnekten oluşmaktadır. Veri setinde yer alan eksik değerler 0 olarak ayarlanmıştır. İlgili tetikleyici yanıtlarının sayısal toplamları da veri setinde 3 adet öznitelik boyutunda olacak şekilde yer aldığı için min-max özellik ölçeklendirme kullanılmış ve veri setindeki ilgili öznitelikler 0-1 aralığında yeniden ölçeklendirilmiştir. Ek olarak, deneysel analiz on kat çapraz doğrulama kullanılmıştır.

\subsection{Kullanılan Sinıflandırıcı Algoritmalar}

$\mathrm{Bu}$ bölümde, deneysel analiz aşamasında kullanılan sınıflandirıcı algoritmalar sunulmuştur. Kullanılan bu algoritmalar; NB, DVM, KNN, karar ağaçları, LR, rastgele orman, GBM, XGBoost, LightGBM, CatBoost, ÇKA şeklindedir.

NB algoritması, Bayes teorimini ve veri setindeki öznitelikler arasındaki koşul bağımsızlığını temel alan bir sınıflandırma algoritmasıdır (Han, Kamber, \& Pei, 2012). Bu algoritma, sınıflandırma işlemindeki hesaplama sürecini basitleştirmektedir. Buna rağmen yüksek doğruluk oranında sınıflandırma performansı göstermektedir. DVM algoritması, sınıflandırma ve regresyon problemleri için sıklıkla kullanılan ve başarılı sonuçların elde edildiği bir yöntemdir. DVM algoritması 
sınıflandırma problemlerinde, doğrusal veya doğrusal olmayan verilerin sinıflandirılmasında kullanılabilen bir denetimli ögrenme algoritmasıdır. DVM ilk olarak iki sınıflı sınıflandırma problemleri için sonrasında ise çok sınıflı sınıflandırma problemlerinde kullanılmıştır (Cortes \& Vapnik, 1995). KNN algoritması, sınıflandırma ve regresyon problemleri için kullanılan, örnek tabanlı parametrik olmayan denetimli öğrenme algoritmasıdır. KNN algoritması uzaklık ve komşuluk sayısı (n_neighbors) olmak üzere 2 farklı temel parametreyi kullanarak sınıflandırma işlemini yapmaktadır. Az sayıda parametreyi incelemesine rağmen sınıflandırma problemlerinde iyi sonuçlar verebilmektedir. Karar ağaçları algoritması, hem sınıflandırma hem de regresyon problemlerinde çok çıktılı olarak kullanılabilmektedir. Karmaşık veri setlerinde iyi bir performans göstermektedir. Çok fazla veri ön işleme gerekliliği olmaması nedeni ile kullanılabilirliği yüksek bir algoritmadır. Birtakım karar mekanizması sistemleri kullanılarak büyük verilerin daha küçük veri kümelerine ayrılması sistematiği üzerinden çalışmaktadır (Safavian \& Landgrebe, 1991). LR algoritması, sınıflandırma problemlerinde kullanılmak amacıyla doğrusal regresyonu temel alan bir sinıflandirma algoritmasıdır (Ruppert, 2004). Rastgele orman algoritması, sinıflandırma ve regresyon problemlerinde kullanılabilen topluluk öğrenmesi yöntemidir. Rastgele orman, karar ağaclarına dayalı olarak torbalama ve rastgele alt uzay algoritmasını birleştiren bir algoritmadır. Her ağaç, veri kümesinin eğitim bölümünün boostrap örneklerine dayalı olarak oluşturulmaktadır (Breiman, 2001). Topluluk öğrenmesi yöntemi olan yükseltme algoritmaları, sıralı bir süreçten oluşmaktadır ve her başarılı işlemde önceki işlemin hatalarını düzeltmeye çalışmaktadır. $\mathrm{Bu}$ algoritmada, birbirini izleyen her süreç bir önceki sürece bağlıdır (Mayr, Binder, Gefeller, \& Schmid, 2014). Yükseltme algoritmaları, eğitilen modelin önyargısını azaltmayı amaçlar. Bu çalışmada, yaygın olarak kullanılan birkaç yükseltme algoritması kullanılmış olup bunlar: GBM, XGBoost, LightGBM ve CatBoost'dur.

ÇKA algoritması ile sınıflandırma işlemi yapılabilmesi için oluşturulan mimari tasarım giriş ve çıkış katmanlarına ek olarak birbirini takip eden 4 adet gizli katmandan oluşmaktadır. Toplam 6 katmanlı mimari tasarım için; giriş katmanında öznitelik sayısı olan 25 kadar nöron, ilk gizli katmanda 64 adet nöron, diğer 3 gizli katmanda sırası ile 32, 16 ve 8 adet nöron kullanılırken, çıkış katmanında sınıf sayısı olan 2 kadar nöron kullanılmıştır. 4 gizli katman için aktivasyon fonksiyonu 'ReLu' olup çıkış katmanı aktivasyon fonksiyonu 'softmax'dir. Optimizasyon fonksiyonu ve kayıp fonskiyonu olarak sırasıyla 'Adam' ve 'seyrek kategorik çapraz entropi' kullanılmıştır. Öğrenme oranı ise varsayılan değer olan 0.001 olarak seçilmiştir. Küme boyutu ise $16,32,64,128$ ve 256 olarak farklı değerlerde algoritmaya dahil edilmiştir. ÇKA modelleri 100 epoch boyunca eğitilmiştir.

Makine öğrenmesi tabanlı sınıflandırıcılar için scikit-learn kütüphanesi kullanılırken ÇKA sınıflandırıcısı için Keras kütüphanesi kullanılmıştır. Tüm sınıflandırıcı algoritmalar Python programlama dilinde Spyder entegre geliştirme ortamında (IDE) oluşturulmuştur. Kullanılan donanım ise NVIDIA GTX 950M'dir. Sınıflandırıcı algoritmaların kullanımı ile elde edilen sonuçlar, karşılaştırılmalı analizlerle birlikte bölüm 4'de gösterilmiştir.Migren oluşumlarının önceden tahmin edilmesi hem önlenmesi hem de hafifletilmesi açısından oldukça önemlidir. Böylelikle hastalar baş ağrıları konusunda daha çok bilgi sahibi olabilirler. Baş ağrılarını tetikleyen durumlar önlenebilir. Sonuç olarak ise hastalar şiddetli migren ağrılarından kurtulabilirler. $\mathrm{Bu}$ destekleyici sağlık sisteminin oluşturulması için makine öğrenmesi ve derin öğrenme yöntemleri, belli migren tetikleyicileri ile migren oluşma durumu arasındaki ilişkiyi analiz etmek için kullanılabilir.

\subsection{Performans Değerlendirme Metrikleri}

Doğru Pozitif (TP), Doğru Negatif (TN), Yanlış Pozitif (FP), Yanlış Negatif (FN) değerleri sırayla; doğru sınıflandırılan pozitif sınıf sayısını, doğru sınıflandırılan negatif sınıf sayısını, yanlış sınıflandırılmış pozitif sınıf sayısını ve yanlış sınıflandırılmış negatif sınıf sayısını ifade etmektedir. Bu çalışmada, sınıflandırıcı modellerin performanslarını daha gerçekci inceleyebilmek amacı ile doğruluk ve F1-skoru metrikleri kulanılmıştır.

$$
\begin{aligned}
& \text { Doğruluk }=\frac{\mathrm{TP}+\mathrm{TN}}{\mathrm{TP}+\mathrm{FP}+\mathrm{TN}+\mathrm{FN}} \\
& \text { Kesinlik }=\frac{\mathrm{TP}}{\mathrm{TP}+\mathrm{FP}} \\
& \text { Duyarlılık }=\frac{\mathrm{TP}}{\mathrm{TP}+\mathrm{FN}} \\
& \text { F1-skor }=\frac{2 \times \text { Kesinlik x Duyarlılık }}{\text { Kesinlik+Duyarlılık }}
\end{aligned}
$$

\section{Deneysel Analiz ve Sonuçlar}

Deneysel analizde, makine öğrenmesi ve derin öğrenme tabanlı sınıflandırıcıların kullanılması ile elde edilen sonuçlar iki farklı tabloda sunulmuştur. Tablo 1'de makine öğrenmesi tabanlı algoritmalar ile elde edilen deneysel sonuçlar gösterilirken Tablo 2'de çok katmanlı algılayıcı algoritması ile elde edilen deneysel sonuçlar gösterilmiştir. Her iki tabloda da doğruluk oranı ve F1skoru bakımından karşılaştırılmalı analizler sunulmaktadır.

Makine öğrenmesi tabanlı algoritmalar ile elde edilen sonuçlar incelendiğinde; NB algoritması \%99.20 doğruluk oranı ve \%93.90 F1-skoru elde etmiştir. DVM algoritması \%99.10 doğruluk oranı ve \%95.20 F1-skoru elde etmiştir. KNN algoritması \%98.80 doğruluk oranı ve \%90.90 F1-skoru elde etmiştir. Karar ağaçları algoritması \%99.30 doğruluk oranı ve \%95.10 F1-skoru elde etmiştir. LR algoritması \%99.40 doğruluk oranı ve \%95.50 F1-skoru elde etmiştir. Rastgele orman algoritması \%98.90 doğruluk oranı ve \%94.90 F1-skoru elde etmiştir. GBM algoritmas1 \%98.80 doğruluk oranı ve \%95.40 F1skoru elde etmiştir. XGBoost algoritması \%99.30 doğruluk oranı ve \%95.00 F1-skoru elde etmiştir. LightGBM algoritması \%99.20 doğruluk oranı ve \%95.30 F1-skoru elde etmiştir. CatBoost algoritması \%99.10 doğruluk oranı ve \%95.10 F1-skoru elde etmiştir. Sonuç olarak makine öğrenmesi tabanlı algoritmalar içerisinde en iyi sınıflandırma performansını LR algoritması elde etmiştir. Özellikle yükseltme algoritmalarına (GBM, XGBoost, LightGBM ve CatBoost) ait parametlerin değiştirilmesi ile başarım oranında ciddi değişmeler olduğu gözlemlenmiştir. Ek olarak KNN algoritmasının doğruluk oranı, komşu sayısı parametresine göre değişkenlik göstermektedir. Sonuç olarak bu algoritmalar ile daha iyi başarım oranlarının alınması mümkündür.

ÇKA mimarisi 16, 32, 64, 128 ve 256 olmak üzere farklı küme boyutlarında 100 epok boyunca eğitilmiş olup elde edilen sonuçlar incelendiğinde; ÇKA mimarisinde küme boyutu 16, 32, 64,128 ve 256 kullanıldığında elde edilen doğruluk oranları sırası ile $\% 99.20, \% 99.70, \% 99.60, \% 99.60$ ve $\% 99.50$ iken F1-skorları 
sırası ile $\% 94.90, \% 97.70, \% 96.90, \% 96.80$ ve $\% 96.20$ 'dir. Küme boyutu 16'dan 32'ye çıkarıldığında doğruluk oranının arttığ gözlemlenmiştir. Sonuç olarak farklı küme boyutları ile eğitilen ÇKA algoritmaları içerisinde en iyi sınıflandırma performansı küme boyutu 32 iken \%99.70 doğruluk oranı ve \%97.70 F1-skoru ile elde etmiştir.

Tablo 1. Makine Öğrenmesi Tabanlı Algoritmalar için Deneysel Sonuçlar

\begin{tabular}{|c|c|c|}
\hline $\begin{array}{c}\text { Kullanılan Sınıflandırıcı } \\
\text { Algoritmalar }\end{array}$ & $\begin{array}{c}\text { Performans Değerlendirme } \\
\text { Metrikleri }\end{array}$ \\
\cline { 2 - 3 } & $\begin{array}{c}\text { Doğruluk oranı } \\
\text { F1-skoru }\end{array}$ \\
\hline NB & 0.992 & 0.939 \\
\hline DVM & 0.991 & 0.952 \\
\hline KNN & 0.988 & 0.909 \\
\hline Karar Ağaçları & 0.993 & 0.951 \\
\hline LR & $\underline{\mathbf{0 . 9 9 4}}$ & $\underline{\mathbf{0 . 9 5 5}}$ \\
\hline Rastgele Orman & 0.989 & 0.949 \\
\hline GBM & 0.988 & 0.954 \\
\hline XGBoost & 0.993 & 0.950 \\
\hline LightGBM & 0.992 & 0.953 \\
\hline CatBoost & 0.991 & 0.951 \\
\hline
\end{tabular}

Tablo 2. Çok Katmanlı Algılayıcı Algoritması için Deneysel Sonuçlar

\begin{tabular}{|c|c|c|}
\hline \multirow{2}{*}{$\begin{array}{c}\text { Küme } \\
\text { Boyutu } \\
\text { (Batch Size) }\end{array}$} & \multicolumn{2}{|c|}{ Performans Değerlendirme Metrikleri } \\
\cline { 2 - 3 } & Doğruluk oranı & F1-skoru \\
\hline 16 & 0.992 & 0.949 \\
\hline 32 & $\underline{\mathbf{0 . 9 9 7}}$ & $\underline{\mathbf{0 . 9 7 7}}$ \\
\hline 64 & 0.996 & 0.969 \\
\hline 128 & 0.996 & 0.968 \\
\hline 256 & 0.995 & 0.962 \\
\hline
\end{tabular}

\section{Tartışma}

Bu çalışma kapsamında, kişisel bilgiler ve günlük aktiviteler gibi tetikleyicilerin migren atağı üzerindeki etkilerinin makine öğrenmesi ve derin öğrenme yöntemleri ile analizi yapılmıştır. Bu kapsamda; stres, uyku durumu, egzersiz yapma durumu, yorgunluk, hormonal değişiklikler, duygusal değişiklikler, hava değişiklikleri, güneş ışığı, gürültü, aydınlatma durumu, kokular, alkol tüketimi, beslenme durumu, kafein tüketimi, sigara tüketimi, tüketilen besinin türü, seyahat vb. gibi çeşitli 22 adet tetikleyicinin yer aldığı bir veri seti kullanılmıştır. Bu veri seti ile birlikte kullanılan sınıflandırıcı algoritmalar ise NB, DVM, KNN, karar ağaçları, LR, rastgele orman, GBM, XGBoost, LightGBM, CatBoost, ÇKA şeklindedir. Tüm bu sınıflandırıcı algoritmalar içerisinde en iyi sınıflandırma performansını, 32 küme boyutu ile 100 epok boyunca eğitilen ÇKA algoritması \%99.70 doğruluk oranı ve \%97.70 F1-skoru ile elde etmiştir. Sonuç olarak bu çalışmada, yüksek bir kestirimci performansa sahip olan ve migren atağının tahminlenmesini sağlayan bir karar destek sistemi önerilmiştir. Yapılması planlanan gelecek çalışmalar arasında, daha fazla tetikleyiciyi içeren bir veri setinin kullanılması ve kullanılan sinıflandırıcı algoritma sayısının artırılması yer almaktadır.

\section{Teşekkür}

Park JW, Chu MK, Kim JM, Park SG ve Cho SJ'ye yapmış oldukları anket çalışması sonuçlarını halka açık olarak paylaştıklarından dolayı bilime yapmış oldukları katkı için teşekkür ederiz.

\section{Referanslar}

Migraineresearchfoundation.org. (2015). Migraine Research Foundation -- About Migraine. Retrieved February 27, 2021, from MRF web site website: https://migraineresearchfoundation.org/aboutmigraine/migraine-facts/

Mayo Clinic. (2020). Trichinosis - Symptoms and causes - Mayo Clinic. Retrieved February 27, 2021, from mayoclinic.org website: https://www.mayoclinic.org/diseasesconditions/migraine-headache/symptoms-causes/syc20360201

Berengueres, J., \& Cadiou, F. (2016). Migraine factors as reported by smartphone users. Proceedings of the Annual International Conference of the IEEE Engineering in Medicine and Biology Society, EMBS, 2016-Octob, 271-274. https://doi.org/10.1109/EMBC.2016.7590692

Liu, C., Holroyd, K. A., Zhu, Q., Shen, K., \& Zhou, W. (2010). Design and implementation of a behavioral migraine management iPhone app for adolescents with migraine. 2010 IEEE International Symposium on "A World of Wireless, Mobile and Multimedia Networks", WoWMoM 2010 Digital https://doi.org/10.1109/WOWMOM.2010.5534985

Garcia-Chimeno, Y., Garcia-Zapirain, B., Gomez-Beldarrain, M., Fernandez-Ruanova, B., \& Garcia-Monco, J. C. (2017). Automatic migraine classification via feature selection committee and machine learning techniques over imaging and questionnaire data. BMC Medical Informatics and Decision Making, 17(1). https://doi.org/10.1186/s12911017-0434-4

Park, J. W., Chu, M. K., Kim, J. M., Park, S. G., \& Cho, S. J. (2016). Analysis of trigger factors in episodic migraineurs using a smartphone headache diary applications. PLoS ONE, 11(2). https://doi.org/10.1371/journal.pone.0149577

Han, J., Kamber, M., \& Pei, J. (2012). Data Mining: Concepts and Techniques. In Data Mining: Concepts and Techniques. https://doi.org/10.1016/C2009-0-61819-5

Cortes, C., \& Vapnik, V. (1995). Support-Vector Networks. Machine Learning, 20(3), 273-297. https://doi.org/10.1023/A:1022627411411

Safavian, S. R., \& Landgrebe, D. (1991). A Survey of Decision Tree Classifier Methodology. IEEE Transactions on Systems, Man and Cybernetics, 21(3), 660-674. https://doi.org/10.1109/21.97458

Ruppert, D. (2004). The Elements of Statistical Learning: Data Mining, Inference, and Prediction. Journal of the American Statistical Association, 99(466), 567-567. https://doi.org/10.1198/jasa.2004.s339

Breiman, L. (2001). Random forests. Machine Learning, 45(1), 5-32. https://doi.org/10.1023/A:1010933404324

Mayr, A., Binder, H., Gefeller, O., \& Schmid, M. (2014). The evolution of boosting algorithms: From machine learning to statistical modelling. Methods of Information in Medicine, 53(6), 419-427. https://doi.org/10.3414/ME13-01-0122 